\title{
On Text Interpretation, Summary Production, and Pragmatic Fatigue in EAP Written Discourse
}

\author{
Aisha M. Alhussain ${ }^{1}$ \\ ${ }^{1}$ Princess Nourah University, KSA \\ Correspondence: Aisha M. Alhussain, Princess Nourah University, Riyadh, KSA. E-mail: \\ amalhusian@pnu.edu.sa
}

Received: March 7, 2017 Accepted: March 29, 2017 Online Published: July 15, 2017

doi:10.5539/ijel.v7n4p197 URL: http://doi.org/10.5539/ijel.v7n4p197

\begin{abstract}
The intent of this interdiscursive endeavor is to argue that EAP text interpretation (reading) and production (writing) can be effectively integrated through the task of summary writing (SW), which academically-oriented students must be able to perform. A discourse-level error analysis enabled us to focus on various features of the summaries which, taken together, indicate how well the (SW) class students had mastered both the goals of text interpretation and the conventions of summary writing, the identification of superordinate and subordinate points, the inclusion of an opening statement of the gist of the primary text, explicit reference to the primary author and text, and successful paraphrasing and representation of substantial claims without pragmatic failure or cross-cultural fatigue. It is a pragmatic feasibility to teach EAP students to be discourse analysts to the extent required by this discourse relevant task, and by learning to do such analysis, they can, in psycholinguistic coinage, integrate formative techniques of comprehension by production and summative techniques of production by comprehension.
\end{abstract}

Keywords: text interpretation, summary production, pragmatic fatigue, written discourse, integrating text interpretation and production, Arab Learners of English, cross cultural communication breakdown, foreigner talk discourse (FTD) breakdown, interdiscursivity

\section{Introduction}

During the past decade or so, much of applied linguistics has been based on discrete paradigms and structuralism. Orality and literacy are categorized in terms of a bifurcation as compartmentalized concepts or dichotomous phenomenon.

The predominant movement towards communicative medium of language and discourse analysis has led to an integration of skills, or at least to classes which are not explicitly divided along the skill parameters and domains (Pysarchyk \& Yamshynska, 2015; Pustejovsky, 2012; Johnstone, 2007; Ezzat, 1995; Abousenna, 1994).

Classroom activities such as those proposed by Seams (2011), Littlewood (1981), Widdowson (1984) call for more interdiscursivity among the productive and receptive modes than is normally possible in a class entitled "reading" or "speaking". By interdiscursivity, Fairclough (1994) describes that one type of discourse can be constituted from a configuration of text types or discourse conventions. Thereby allowing any piece of discourse to manifest features belonging to oral and literate modes for certain stylistic effects. Taiwo \& Salami (2007) embraced the same trend of interdiscursive thought.

However, interdiscursive approaches in literate discourse, the old ways remain, perhaps because of the structure of the academic world in which "specialization" is a keyword. Hence, despite the call for more integrated approaches to reading and writing (Keh, 1994), second language research has persisted in treating reading and writing as detached areas. Witness the publication of two volumes by Longman: Reading in Foreign Language and Learning to Write: First Language /Second Language, or the establishment, at the University of Aston in Birmingham, of the new journal, Reading in a Foreign Language. Also, a glance at renowned publisher, their catalogs reveals that textbooks are still often classified as orality or literacy texts.

Within the domain of English for academic purposes, there seems to be little justification for the rigid separation of reading and writing skills. In authentic scenarios, a writer must often write about what they have read, such as the student writing a term paper, or the businessman responding to a letter from an associate. In fact, a reliable 
survey of academic departments in 34 American Universities (Bridgeman \& Carlson, 1994) revealed that writing summaries of brief articles is a task required by $68 \%$ of the departments and that $74 \%$ of them require brief research papers. In contrast, tasks labeled expository writing are limited to undergraduate English programs enrolling non-native speakers of English and the diagnostic courses of academic writing are tailored to fulfill their needs. We can conclude that EFL courses designed to prepare students for academic work, particularly at the undergraduate level, must integrate reading and writing into one melting pot (Zikri, 1990). Goen \& Gillotte-Tropp (2003) states that "students in the integrated course can meet the cognitive challenges of learning to write as readers and read as writers". (p. 108) Some textbook writers recognize the need to combine reading and writing in academically-oriented courses (Arnaudet \& Barrett, 1984; Aebersold et al., 1985; Choe \& Butt-Griffler, 2015).

Many researches in EFL field have recognized the positive effect of teaching reading to develop writing skills (Hirvela, 2004; Tuan, 2002). Aldosari's study (2011) explored the effect of teaching reading and writing integratively in an EFL context to improve writing skills. Morcia \& Olshtain (2002) states that writing activity starts with reading texts that are used as a model for writing.

More studies were done to examine the role of reading and writing in summarization (Cohen, 1994; Yu, 2008) but most of them used it as a reading tool. Asencion's study (2008) explored the correlation between reading, writing and summary writing. Li (2014) conducted a study to explore the role of reading and writing in summarization. The results showed that writing was more effective on the task of summarization than reading.

I suggest continuing the pragmatic trend by suggesting a discourse relevant approach to integrate reading and writing skills through the activity of summary writing. This paper describes and illustrates an approach at integration of both skills associated with the process of summary writing. I describe a pedagogic approach and some problematic issues associated with the process. I also describe here a sample of summaries produced by an EAP program designed to prepare students for university work.

\section{Academic Interdiscursivity in Reading \& Writing Summarization}

Interdiscursivity is the use of implicit or explicit aspects of a discourse from other related discourse. "The inter-discourse analysis approach" that I am suggesting aims to help students meet the goals set out by Widdowson (1978) "What the learner needs to know how to do is to compose in the act of writing, comprehend in the act of reading, and to learn techniques of reading by writing and techniques of writing by reading" ( $\mathrm{p}$. 144).

In EAP programs, we were specifically concerned with preparing students for a type of academic writing which involves skill in reading for both explicit and implicit information. Students need to be able to expertly summarize the main ideas, and then appropriately frame those ideas within the context of their writing. Instruction included comparing the students' summaries both with the original text and to other students' summaries. We used a discourse analysis approach because it encourages careful reading and conscious awareness of text organizing strategies, and because it focuses attention on the text that the students have produced.

To illustrate this I will first provide a working definition of the task of summary writing, focusing on the interpretation of texts (reading) and production of summaries (writing). I also present examples from a set of student summaries to illustrate how they were organized and framed in relation to the textbook to provide conventions of summary writing. In addition to how they corresponded to the original texts in the selection of details in paraphrasing. These examples are meant to illustrate how inter-discourse analysis can be materialized in EAP classroom instruction.

Second, interdiscursivity affects academic writing by tertiary students from non-English speaking backgrounds. These interdiscursive effects are analyzed in terms of how students directly draw on other texts in their writing, and how they adopt discourse conventions to shape their texts. I shall draw on examples from student writing to argue that inter-discourse not only shapes what kinds of things can be enounced but also conditions the act of enunciation.

\section{The EAP Course Program}

The summaries described in this paper were written by 40 graduates admitted to the EAP program under the auspices of the English Language Center, at AlGhad Colleges in Kingdom of Saudi Arabia. All students in this twelve-week course had been accepted to pursue MA studies and had joined for one term to improve their EFL skills while embarking upon their required courses.

The students met with their reading instructor three hours per week during which they worked on traditional 
reading skills such as skimming, scanning, and outlining as well as answering and reading comprehensive items based on advanced-level reading passages. As part of the program, they also read longer articles on foreign culture and quality assurance issues and then discussed in a "Seminar Skills" class. Also, once a week they were given an article to read during the reading class and asked to write a summary. The summaries were discussed and evaluated in the writing class, which met five days a week for one hour. All articles used in this way were authentic presented in their entirety, and ranged across some disciplines. Additional work in summary writing was provided when the students prepared research papers in their fields as part of the requirements of the program.

\section{The Task of Summary Writing}

Summary writing is an activity which requires students to utilize a number of important skills in an authentic communicative situation. The process of summarization is here defined as creating a secondary text which is shorter in length but which represents the thesis and main idea of a primary text. The following diagram visually represents this process:

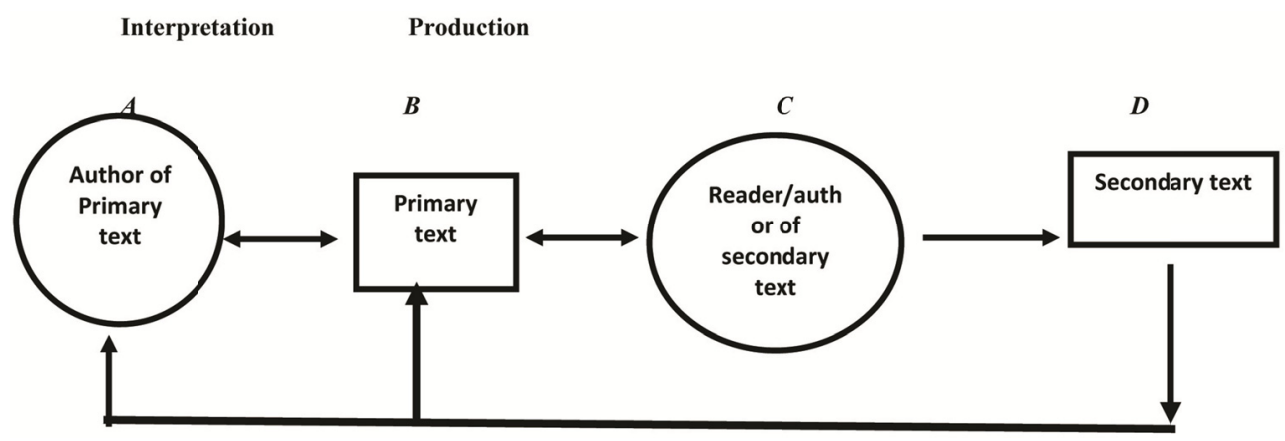

Figure 1. EAP text interpretation and production

In figure one, the bidirectional arrows between $\mathrm{A}$ and $\mathrm{B}$ are meant to indicate that a written text refers to the author, explicitly using first person pronouns, or implicitly through style and word choice. The bi-directional arrows between $\mathrm{B}$ and $\mathrm{C}$ indicate the interactive quality or the schematic processing of the reading process. They are meant to show that reading is not merely receptive, but that each reader creates a "reading" of a text based on his/her interpretation, which involves familiarity with the subject matter, the genre, and the language of the text. The unidirectional arrows from D to B and from D to A indicate that a summary, according to text and author by using the author's name, a third- person pronoun, or the title of the text. Another rule found in textbooks is to "be objective," which is indicated on the diagram by the one- way arrow between $\mathrm{C}$ and $\mathrm{D}$. We take this to mean that a secondary text should not refer to the secondary author. In other words, the use of a first-person pronoun is inappropriate in an objective summary, as in a statement of the opinion of the secondary author.

The portions of the summarization process that I am directly concerned with in this paper are labeled "interpretation," and production "on the diagram that is, the strategies students use in efficient reading of the text and in writing their objective summaries. I briefly discuss each of these in turn to provide a framework for the subsequent analysis.

\section{EAP Text Interpretation and Production}

Focusing on the "interpretation" area of summarization I have adapted from Widdowson and Urquhart's research (1976) in reading for academic purposes four goals of a good reader: 1) recognizing the overall structure of the text; 2) recognizing superordinate concepts; 3) recognizing the relationship between superordinate and subordinate concepts; 4) Integrating text materials into one's knowledge structure or schematic knowledge in Carrel's term $(1987,1983)$.

As Widdowson and Urquhart point out, very little is known about the quantity and quality of the information that the average student acquires through reading, as the activity is covert. However, I suggest that one way of assessing reading comprehension is by evaluating the student's ability to write a summary of what he has read, since a summary should reflect an understanding of the overall structure of a source text, including the relationships between superordinate and subordinate concepts. Moreover, I suggest a process of assessment that might provide a means of increasing comprehension, as students compare their summaries of a text with those 
written by other students.

In addition to concerns of interpretation, there are concerns of production, i.e., writing. I found that students needed explicit training in writing summaries, including practice in writing for a variety of purposes and audiences as well as experience with conventions of summary writing (Li, 2014). Part of the instructional task, then, was to make clear some typically unstated assumptions about what constitutes a summary and for what purpose one might be asked to write one. Since the authors of secondary text in our study were EAP students, I needed to consider the purpose of summary writing from their perspective. Is it simply a decontextualized activity to be performed in the EAP class, or is it a communicative skill that is useful for any academic writing? While no writing is done within the context of the EAP class is the same as that done for a class within an academic discipline, summarization is a skill that is expected of college students (Cho \& Brutt-Griffler, 2015).

By coordinating our reading and writing classes with a "Seminar Skills" class, I was able to develop a number of contexts in which students were required to use summary skills. These included; 1) answering questions on an essay examination; 2) writing the literature review of a research report; 3) preparing and giving seminar report on a particular article or group of articles.

Besides being presented with a variety of context in which summary is needed, students were given specific training in the "conventions of summary writing." my source for these conventions was the agreed-upon rules found in textbooks designed for Freshman English; 1) include all the main ideas; 2) use your words; and 3) acknowledge the source of the original information (title and author). In contrast to the typical textbook approach to summary writing, however, instruction included a discussion of the implicit cultural biases in these "rules," and I presented some sample summaries to illustrate how the rules work and how they can be broken.

The definition of summary writing presented is an attempt to clarify the task in terms of relationships, the relationship of the student writer (secondary author) to the primary author, as all diagrams must be, and it neglects many important aspects of interpretation and production, but it represents a step towards a better understanding of what the act of writing a summary entails.

\section{Analysis of Student Summaries}

On the seven articles, which the students read and summarized in class, I selected one to analyze and present here as an example of how discourse analysis can be used as a pedagogical tool. "The Battle for Quality Begins" by Jeremy Main was third in the series of articles. So, by the time students wrote this summary they had received explicit instruction and evaluation of earlier work.

The research method involved first analyzing the primary text and then analyzing the student- produced secondary text to determine how they chose to "re-present" the original material. Therefore, I found it necessary to devise a notational system which allowed to compare the text. Some text analysts, such as Kintsch \& van Dijk (1978), have reduced text to lists of propositions made up of the predicate and one more argument. I have chosen instead to use notational system which is closer to an outline structure because 1) it provides a visual representation of the superordinate and subordinate points which is accessible to the students, and 2) it allowed to make a comparison of the student summaries with primary text by charting the incidence and order of mention for each of the points in the outline.

To validate the outline and our interpretation of the primary text, I consulted as "Specialist informant" discourse analysis (Selinker, 1979) an instructor of business management who was familiar with technical aspects of the topic of the article-quality control. After giving his interpretation of the article, he read a version of the outline we had prepared. He agreed with the analysis of the structure; I later revised the outline per his suggestions (See Appendix A for the revised outline). Also, I created a summary based on his outline which I shared with students in an evaluation session.

Once I had an "ideal" representation of the text, I then compared each of the student summaries with it. The three major factors we considered in evaluation the student texts were organization strategies, knowledge of the conventions of summary writing, and ability to paraphrase.

\section{Organizational Strategies}

How should a summary be organized? Should it follow the rhetorical structure of the primary text, or should it reflect the secondary author's organization? I found considerable disagreement on this question among textbook writers: Some texts say that for an objective summary the order should be the same; others recommend that summary writers use their organization of idea. Since there was no clear rationale for either view, we decided to leave the question open, and thus, the instructions the students received before writing the summaries did not address this point. However, when I began to analyze the student's texts, it became clear that students were using 
different strategies in organizing their texts. The analysis of summaries indicates that the student used three basic organization strategies: 1) paralleling the sequence of the superordinate points of the primary text; 2) including the superordinate points of the primary text but in a different order; and 3) focusing on one point in the primary text.

These strategies of the organization are roughly comparable to the macro rules proposed by Kintsch \& van Dijk (1978) modified by Brown \& Day (1983), who suggest that the processes of deletion, super ordination, selection, and invention underlie methods of summarization. In other words, students whose summaries paralleled the organization of the primary text, per this view, were utilizing processes of deletion, whereby they eliminated nonessential material. In contrast to "Copy delete" method describe by Brown \& Day (1983). However, the students in the present study (with one exception) did not copy verbatim from the primary text. They could paraphrase to some extent. Roughly half of the students used the strategy of creating sequence parallel to the original.

Those who used a different order of organization from the primary text were, in Kitsch \& van Dijk's terms, utilizing processes super ordination, selection, and invention, whereby they created new ways of putting the ideas together. For example, the primary author, Jeremy Main, cites three factors that determine good quality, good tools, workers, and effective management. However, no superordinate term is provided "reasons why Japanese products have excellent in quality." A comparison of this student's summary with the primary text clearly shows this phrase to be misguided, since the primary author was not referring specifically to Japanese products.

The third strategy, which focused on one point, was used by only nine students. I am not sure why students would fix on one point and ignore the others. Since the writing was done within a class period of fifty minutes, it is possible that they ran out of time, but in one case at least, we believe that the student misinterpreted the intent of the task, despite previous summary writing assignments.

Barring constraints of time, strategy number one, in which the students' summary parallels the original, is the easiest strategy to follow. The rhetorical framework is supplied by the primary author, and the student simply should follow it for the organization of this summary. The other two strategies are somewhat more difficult in that they require more interaction with the text. The student reads the primary text and then must decide how to represent the material. Further, in strategy three, the student focuses on one point, by which the information in the text is synthesized to one basic idea or thesis. The success of the latter strategy depends to large extent, on the ability of the student to match the thesis of the primary author.

I suggest that whether one strategy or another is considered appropriate depends upon how the summary is to be used. For example, if students need to provide a summary for introducing an article to a seminar group. Then clearly a summary which focuses on only one point would not be representative of the author's work and would be inappropriate. However, if students were putting together material for a term paper they would need to mention only the point or points which pertain to their topics. In this case, strategy three would be the most useful and efficient. Therefore, the instructional approach to the issue of the organization was to point out that whether a strategy is "correct" depends on the purpose for writing a summary.

\section{Conventions of Summary Writing}

The second set of factors considered has to do with conventions of summary writing, including explicit mention of the title, author, and source of the primary text, as well as a statement of the gist of the article. Although these features are the most easily taken care of by instruction and the most easily identifiable features of the student summaries examined here, even advanced EAP students have difficulty handling them appropriately.

Mentioning the title of article posed little problem for students, once they had been instructed to do so and had been given several complaints of formulae for this purpose. Students mentioned the author in their summaries, with these including both first and last name (perhaps by using both names the students eliminated any possibility caused by unfamiliarity with English names). In most cases, mention of the author was made in the opening statement. Only a few students included explicit references to the primary text/author thought, although this convention had been discussed as a way of maintaining objectivity. Two examples from students' summaries illustrate this point:

a) For the recovery of competitiveness in quality, he suggests.

b) In his opinion, the main reason is that.

Although it is clearly redundant to top frame information in this way, it is recommended by some textbook authors as a strategy for students (Reid, 1982). Mention of the source document presented more of a problem. In 
one summary, the students were given as a sample, the author's last name and date of publication were mentioned, e.g., Main 1980, with the full source cited as a footnote to the summary. Since only half of the students included any mention of the source document, it seems they were not convinced that it was necessary. Clearly, in a situation where the teacher has distributed an article, and all the students are writing summaries of the same article, it appears unnecessary. However, in a research paper, this information would have to be incorporated into the text.

Another feature relating to conventions of summary writing is the framing of an opening statement, which typically includes, in addition to a reference to author and title, a statement of the gist of the article. Frequently, this statement includes a term such as "explains, discusses, describes" which is called a controlling term. The student summaries showed a variety of opening phrases, which the following examples illustrate: (The controlling terms are underlined)

1). In the article "The Battle for quality Begins", Jeremy Main explains about quality control (QC) in the U.S., the theories of which were developed in the USA, but they are surpassed by the Japanese products recently.

2). In an article entitled "The Battle for quality Begins", the author argues that although the quality of American product is said to be getting poorer compared to that of Japanese, it is not because of the low quality of American workers, but because of the difference in management attitude toward quality control between the two countries.

3). Jeremy Main, in his article "The Battle for quality begins", confesses that while Americans have been teaching the principles of quality to Japanese with excellent results, the Americans cannot achieve quality as effectively as the Japanese do.

4). This article "The Battle for quality Begins" by Jeremy Main (Fortune), discusses quality of American products.

5). In the article "The Battle for quality Begins" Fortune, Jeremy Main explains the reason American products lost its competitive power in quality, especially in comparison with Japan.

These examples are intended to illustrate difficulty most students had in choosing an appropriate controlling term, as well as in making a concise statement of the gist, In Examples (1) and (5), "the students" use of the term "explain" is problematic for both semantic and syntactic reasons. To use this term appropriately, students need to know what an "explanation" entails, and they need to know how the word functions in a sentence. Example (3) illustrates a creative choice of controlling term, perhaps reflecting the writer's culturally- determined response to the admission that American products were losing their competitive edge. A term such as "discuss", in Example (4), on the other hand, is so general that it tells nothing about what the primary author was doing in the article. Some students avoided the problem of choosing a controlling term by using the phrase "according to".

6). According to article entitled "The Battle for quality begins", (Written by Jeremy Main, on Fortune), America's leadership in quality has been eroding.

7). This is the article written by Jeremy Main in Fortune.

Although the exercise can be devised to give students practice in using a variety of introductory phrases (Mekay \& Rosenthal, 1980), the choice of term for referring to a particular article depends on an accurate reading of the text.

To use these terms effectively, the summary writer should interpret the intent of the primary author that is, arguing, discussing, explaining, etc. In other words, formulae for introducing quotations or summaries are useful only if the reading is effective, a point often overlooked by textbook writers.

In the classes, the opening statement produced by students (examples 1-7 above) were typed and distributed for discussion. The students and instructor together evaluated the effectiveness of various tactics, including the choice of the controlling word, always with reference to the primary text. Clearly, the construction of such statements deserves to be focused on in summary writing because it represents the synthesis and distillation of the overall structure and propositional content of the article, skills mentioned earlier as characterizing the goals of good reading.

\section{Interpretation and Paraphrasing}

Earlier in this paper, I discussed the relationship between reader and text, indicating the belief that reading is an interactive process. The literature on reading the research, especially the summary in Widdowson \& Urquhart (1976), confirms the notion that the reader constantly interacts with the author, matching up what is in the text with the conceptual structure he already has. The responsible learner, the creative learner, brings him/herself to bear on what is being read (Badrawi, 1994; Johnson, 1981; Carrell \& Eisterhold, 1983). This substantial issue of 
schema theory is tied closely to the concept of interactivity and integrability in text comprehension and production.

While it is impossible for researchers to determine exactly how the students were matching up what was in the text with their conceptual structures, it is possible to make an inference regarding their interpretations, based on a comparison of the primary text with paraphrase developed by students within the context of their summaries. Therefore, in this section, examples of students' paraphrases are presented and compared with sentences from the primary text that is the source of the paraphrase.

The first set of examples illustrates problems of deletion, that is, what the writers left out that may have changed what the primary author intended or said.

In Table 1, the left- hand column presents the student paraphrases and the right-hand column supplies the information which appeared in the original and was deleted in the paraphrase. This deleted information consists, for example, in (1) a factual discrepancy in terms of time: "before" vs. "before and during" World War II.

Table 1. Omissions in paraphrase

\begin{tabular}{|c|c|}
\hline Omissions in paraphrase & Factual discrepancies \\
\hline 1. The principles for improving quality were developed in the U.S. before world war II. & "before and during." \\
\hline $\begin{array}{l}\text { 2. But Japanese realized its importance and acquired the power. Now two scholars who } \\
\text { taught in Japan are teaching the Americans. }\end{array}$ & Two American scholars. \\
\hline $\begin{array}{l}\text { 3. Since the principles improving quality were shown, Japanese companies have kept } \\
\text { them and developed with high-speed, inviting W. Edwards Deming and so on. }\end{array}$ & The omission of by-phrase. \\
\hline
\end{tabular}

Examples (2) and (3) indicate discrepancies of a different type. Reading these examples, one might incorrectly assume that the scholars who taught the principles of quality control were Japanese, whereas a major point of the article is how well the Japanese adapted principles of quality first espoused by an American scholar.

I have already mentioned the importance of recognizing the overall structure of a text, i.e., its organization beyond the sentence level. I assume that while the 'meaning" of a text is not simply the sum of the meanings of its individual sentences, each sentence contributes to the overall meaning and the way a student interprets an individual proposition can color his interpretation of the whole: Misinterpreting any proposition can lead to greater overall misinterpretation.

I suggest that this is especially true when it comes to assessing the strength of an author's claim. Considering the examples in Table 2, we found that some of the problems in paraphrasing are associated with misinterpretation of grammatical features, such as models, verb tense, and adverbs. In (1), for example, while the primary text indicates a slow process of erosion of leadership in quality control, the student paraphrases this process as either completed - "lost" or as occurring more rapidly — "has been eroding".

Example (2), on the other hand, represents a more serious misinterpretation. The original text makes the point that the United States is having problems with remaining competitive although "U.S. companies have steadily improved quality ". The student's paraphrases indicate that quality control has been totally neglected or forgotten.

The student's paraphrase in example (3) represents the quality of products made by American workers as inferior to those same products made by Japanese or German workers; the primary text, however, says American workers (and presumably the products they make) are "as good as anyone". The point made by the primary author is that the difference is in management. This student at least has neglected to recognize the point.

Finally, we see in example (4) how models can be variously interpreted. The model may is interpreted by one student as will and by another even more strongly. Misinterpretations such as these can lead to serious and unwitting errors in comprehension for the student as a reader and as a writer.

We suggest that problems with paraphrasing exemplify what Jenny Thomas (1982) calls "pragmatic failure" "an inability to understand what is meant by what is said". Either because of the linguistic constraints placed on interpretation by limited language proficiency or other linguistic constraints related to familiarity with the subject matter or even personal opinion, the force of the primary author's proposition has been misinterpreted. Such "pragmatic failure" is a type of cross-cultural communication breakdown which can have serious consequences for non-native speakers engaged in academic work. In a recent paper on hedging in academic discourse, Rounds (1982) proposed that being aware of when and how writers negotiate the strength of their claims is an important receptive and productive skill. Summary writing, by providing a single contained 
discourse, lends itself neatly to analyzing how the strength of claim is handled within a particular text. Also, immediate comparison with the original, as we have done, here can indicate to the students exactly where they are misinterpreting.

Table 2. Strength of claim

\begin{tabular}{ll}
\hline Strength of Claim & Original Text Extract \\
\hline $\begin{array}{l}\text { 1. Main explains the reason American products lost its competitive } \\
\text { power According to the article, American's leadership in quality has } \\
\text { been eroding. }\end{array}$ & $\begin{array}{l}\text { American's leadership in quality has been almost imperceptible } \\
\text { eroding for years. }\end{array}$ \\
$\begin{array}{l}\text { 2. While American industries forget to control quality Japanese } \\
\text { industries have made efforts to operate well. }\end{array}$ & $\begin{array}{l}\text { While U.S. companies have steadily improved quality, they are } \\
\text { coming under pressure largely because the Japanese have advanced } \\
\text { - While quality control was neglected in the old days in the United } \\
\text { by leaps. }\end{array}$ \\
$\begin{array}{l}\text { States. } \\
\text { 3. The quality of products made by American workers in Japanese or }\end{array}$ & $\begin{array}{l}\text { Under proper management, the U.S. worker is as good as anyone. In } \\
\text { German factors in U.S. is almost the same as that in Japan or or the best German and Japanese plants are in the U.S. }\end{array}$ \\
$\begin{array}{l}\text { Germany. } \\
\text { 4. It will take about } 10 \text { years to catch up with Japan. }\end{array}$ & It may take 10 years to catch up with the Japanese. \\
\hline
\end{tabular}

\section{Concluding Remarks}

This discourse-based endeavor analyzed EAP learners' summary writings and suggests that whether one strategy or another is considered appropriate, would rely upon how the summary is to be used and consider authentic context. By using discourse level analysis strategies EAP learners were able to recognize the overall structure of the text, superordinate concepts and the relation to subordinate concepts to (or "intending to") integrate text materials. This further raised their awareness and enriched their own knowledge structure without strategic relapse into pragmatic failure or cross-cultural fatigue. More micro-ethnographic research should be assigned to EAP learners' interpretive competence, a schematic structure of knowledge and pitfalls of foreigner talk discourse (FTD) breakdown.

\section{References}

Abousenna, M. (1994). The role of English in the knowledge society. Proceedings of 14th National Symposium on English Language Teaching, CDELT, Ain Shams University, Cairo.

Aebersold et al. (1985). Critical thinking, critical choices. Englewood Cliffs, N.J.: Prentice-Hall.

Aldosari, H. (2011). Effects of integrating reading and writing during the reading process on EFL English writing in a Saudi college course: A quasi experimental study. Forum Internacional Sobre Pratica Docent Universitaria.

Arnaudet, M., \& Barrett, M. (1984). Approaches to academic reading and writing. Englewood Cliffs, N.J: Prentice-Hall.

Asencion, Y. (2008). Investigating the reading-to-write construct. Journal of English for Academic Purposes, 7(3). https://doi.org/10.1016/j.jeap.2008.04.001

Badrawi, N. (1994). Culture, reading and the foreign language learner: the effect of culture on reading comprehension. Proceeding of 13th National Symposium. CDELT, Ain Shams University, Cairo.

Bridgeman, C., \& Carlson, A. (1994). Academic English. Modern Language, 5(2).

Brown, L., \& Day, J. (1983). Macro-rules for summarizing texts: the development of expertise. Journal of Verbal Learning and Verbal Behavior, 22(1). https://doi.org/10.1016/S0022-5371(83)80002-4

Carrel, P. (1987). A view of written text as a communicative interaction: Implications for reading in a second language. In J. Devine et al. (Eds.), Research in reading in English as a second language. Cambridge: Cambridge University Press.

Carrel, P., \& Eisterhold, I. (1983). Schema theory and ESL reading pedagogy. TESOL Quarterly, 17(4). https://doi.org/10.2307/3586613

Cho, H., \& Brutt-Griffler, J. (2015). Integrated reading and writing: A case of Korean English language learners. Reading in a Foreign Language, 27(2).

Cohen, A. D. (1994). English for academic purposes in Brazil: The use of summary tasks. In C. Hill \& K. Parry 
(Eds.), From testing to assessment: English as an international language. London: Longman.

Ezzat, A. (1995). Culture: A two-way direction. Proceeding of 15th National Symposium on Dialogue of languages and English language Education. CDELT, Ain Shams University, Cairo.

Fairclough, N. (1994). Discourse and social change. Cambridge: Polity Press.

Goen, S., \& Gillotte-Tropp, H. (2003). Integrating reading and writing: A response to the basic writing "crisis". Journal of Basic Writing, 22(2).

Hirvela, A. (2004). Connecting reading and writing in second language writing instruction. Ann Arbor MI: The University of Michigan Press. https://doi.org/10.3998/mpub.23736

Johnson, P. (1981). Effects on reading comprehension of language complexity and cultural bargaining of a text. TESOL Quarterly, 15(2). https://doi.org/10.2307/3586408

Johnstone, B. (2007). Discourse analysis. New Jersry: Wiley-Blackwell.

Keh, C. (1994). A design for a process approach to writing courses. English Teaching Forum, XX Vliii.

Kintsch, W., \& Dijk, V. (1978). Toward a model of text comprehension and production. Psychological Review, 58(5). https://doi.org/10.1037//0033-295x.85.5.363

Li, J. (2014). The role of reading and writing in summarization as an integrated task. Language Testing in Asia, 4(3). https://doi.org/10.1186/2229-0443-4-3

Littlewood, W. (1981). Communicative language teaching. Cambridge: Cambridge University Press.

Main, J. (1980). The battle for quality begins. Fortune, 12(2).

Mekay, S., \& Rosenthal, L. (1980). Writing for specific purposes. Englewood Cliffs, N.J.: Prentice-Hall.

Murcia, M., \& Olshtain, E. (2002). Discourse and context in language teaching: A guide for language teachers. Cambridge: Cambridge University Press.

Pustejovsky, J. (2012). Language as action. India: Transatlantic Publishers.

Pysarchyk, L., \& Yamshynska, V. (2015). The importance of integrating reading and writing for the EFL teaching. Advanced Education, 3.

Reid, J. (1982). The process of composition. Englewood cliffs, N.J.: Prentic-Hall.

Rounds, P. (1982). Hedging in written academic discourse: Precision and flexibility. (Unpublished paper) University of Michigan.

Seams, F. (2011). Reading and writing incorporated. Japan: Sakoma Books, Sakoma.

Selinker, L. (1979). On the use of informants in discourse analysis and language for specialized purposes. IRAL, 17(2). https://doi.org/10.1515/iral.1979.17.1-4.189

Taiwo, R., \& Salami, F. (2007). Discourse acts in antenatal clinic literacy classroom in South-Western Nigeria. Linguistik, 31(2).

Thomas, J. (1982). Cross-cultural pragmatic failure. Applied Linguistics, 4(2). https://doi.org/10.1093/applin/4.2.91

Tuan, L. (2012). Teaching writing through reading integration. Language Teaching and Research, 3(3). https://doi.org/10.4304/jltr.3.3.489-499

Widdowson, H. (1978). Teaching language as communication. Oxford: Oxford University Press.

Widdowson, H. (1984). Learning purpose and language Use. Oxford: Oxford University Press.

Widdowson, H., \& Urquhart, A. (1976). K.A.A. U research project in reading for academic purposes. Mimeo: Edinburgh University.

Yu, G. (2008). Reading to summarize in English and Chinese: A tale of two languages? Language Testing, 24(4). https://doi.org/10.1177/0265532208094275

Zikri, M. (1990). The linguistic and situational validity of an undergraduate course in reading and essay. Occasional Papers, 12(1). 


\section{Appendix A}

\section{OUTLINE THE BATTLE FOR QUALITY BEGINS}

I. U.S attempts to reverse decline of American leadership in quality.

A. Paying more attention to quality specialists.

B. Demanding better components from vendors.

C. Meetings of workers.

II. Pressures on U.S. companies because of Japanese advances.

A. Japanese have emphasized quality.

1. They have built on a foundation of theories developed in the U.S.

2. They have made quality the weapon that wins the world's markets

B. Results of Japanese efforts.

1. According to one expert, Robert E. Cole, "their best are better than our best factories.

2. American consumes favor Japanese products.

III. Principles for improving quality developed in U.S. before and during World War II.

A. These principles exported to Japan; neglected in U.S.

1. Key figures in introducing ideas to Japan.

2. W. Edwards Deming, statistician.

3. Joseph M. Juran, Western Electric quality manager.

B. Principles are deceptively simple.

1. Count defects, analyze them, identify the source, make corrections and keep a record of results.

IV. Effective quality control involves a whole industrial process.

A. Not enough to have inspectors: quality must be built in.

B. Factors of good quality.

1. Good tools.

2. Good workers.

a. Although American workers have been criticized for the decline of work ethic, the author believes the American is as good as anyone.

3. Effective management.

a. Attitudes of management account for the biggest difference between Japanese and Americans figure that some failure is unavoidable, whereas Japanese shoot for perfection.

b. Attitudes in American management are changing, but managers need training as well as enthusiasm.

c. Economic Factors.

\section{Copyrights}

Copyright for this article is retained by the author(s), with first publication rights granted to the journal.

This is an open-access article distributed under the terms and conditions of the Creative Commons Attribution license (http://creativecommons.org/licenses/by/4.0/). 